\title{
The research and application of electronic technology
}

\author{
Xiaotian Wang ${ }^{1, a}$, Jinyu Wei $^{2, b}$ \\ ${ }^{1}$ School of management, Tianjin University of Technology, Tianjin 300384, China \\ ${ }^{2}$ School of management, Tianjin University of Technology, Tianjin 300384, China \\ a1025847707@qq.com, bweijinyu2010@126.com
}

Keywords: electronic technology, development prospect, application research.

\begin{abstract}
Electronic technology is a new technology with the advent of the information age categories emerged gradually, along with the rapid development of network technology, electronic technology has been widely used in different fields In this paper, analyzed the electronic technology based on the development situation of our country, and the direction of development of electronic technology in the future are discussed. And mainly studies the electronic technology in every industry in the application.
\end{abstract}

\section{Introduction}

Electronic technology has promoted the rapid development of human society, and created a huge economic wealth for the people, made a great contribution to improve the production efficiency, improve the living standards of the people ${ }^{[1]}$. From the view of the world, electronic technology in people's production and life applications is very extensive, especially in the economic base of industry started earlier, developed countries, no matter when or where, can feel the infinite charm of electronic technology.

The rapid development of electronic technology, the development of the society needs of the development of electronic technology electronic technology is also an important opportunity. The development of electronic technology in China form the corresponding industrial scale, it must be based on the actual situation of the development of Chinese, learn from foreign experience, out of a road with Chinese characteristics ${ }^{[2]}$. From the research and analysis of foreign advanced technology, gradually embarked on independent innovation, innovative interdisciplinary infiltration, the innovation of technology from the electronic device selection and circuit structure transformation, which is the development of the electronic technology innovation especially useful. At the same time should also be from the application of new materials science and technology, equipment manufacturing process continuously and promote the practical application of electronic technology, integrate the three part: application, technology innovation and marketing. And promote strongly the development of China electronic technology into productive forces is highly significant, rapid promotion of the sustainable development of the national economy.

\section{The application of electronic technology in the industry}

On the whole, compared with western developed countries, China's electronic technology started relatively late, at present has not been able to develop to mature degree, still needs further research and practice. At present, relatively successful application has the following several aspects.

The sensor technology. The arrival of the new technological revolution, the world entered the information age. In the course of the use of information, we must first solve the problem is to obtain accurate and reliable information, and the sensors are the main ways and means to obtain information of nature and production. The sensor is a detection device, can feel the measured information, and can detect the sensed information, according to certain rules to transform into electrical signals or other required information in the form of output, to meet the information transmission, processing, storage, display, record and control requirements. It is the most important link for realizing automatic 
detection and automatic control. The sensor can be measured by induction, get some information, and the information is converted into electronic signals can be recognized by the system, through the conversion of the induction sensor information, and input to the detection system, intelligent detection, monitoring and other aspects of the system function, therefore, the detection of information in various industries in the application of relatively widely. The induction into a recognizable signal components. The sensor through the conversion of the signal, the corresponding parameters of detection system, realize the monitoring, monitoring, intelligent monitoring and therefore, is widely used in various industries and fields of information ${ }^{[3]}$. At present, the sensor technology in our country, widely used in transportation, construction, disaster warning, medicine, industry, agriculture, environmental protection, energy and other aspects. In order to obtain information from the outside world, must rely on the sense organ. In modern industrial production, especially in the automatic production process, various sensors are used to monitor and control the various parameters in the production process, make the equipment work in normal state or state, and to reach the best quality products. So we can say, without a large number of good sensors, the modernization of production will lose the foundation. Based on the study, a more prominent position sensor.

The power supply module. In electronics, the two power module DC converter has been very commercial, it is the use of high frequency PWM technology. With the development of electronic technology, integrated circuit, the power supply module is also more and more high, the main requirements of miniaturization of the power density of the power module has higher requirements.

The frequency converter. Institute of electronic technology, including in the frequency converter, is mainly reflected in the AC motor variable frequency speed regulation, this technology plays an irreplaceable role in the power system, but also can save energy, the main circuit is generally used to from AC to DC switching and routing. Converted to a fixed DC voltage through the rectifier, high frequency inverter consists of a transistor has great power, and then converted by the DC voltage, a variable frequency AC output to output.

The digital watermarking technology. Electronic document is a new product which appears with the rapid development of computer technology, electronic document refers to people in the form of social activities, computer disk, SSD, disk and CD chemical magnetic materials as the carrier, the electronic document text, and picture material depend on computer system access and can be transmitted in a communication network ${ }^{[4]}$. It mainly includes electronic documents, electronic mail, spreadsheets, text documents, electronic drawing paper and electronic version. Digital watermarking technology is some identifying information (i.e., digital watermarking) directly into the digital carrier (including multimedia software, documentation, etc.), but does not affect the value of the original carrier, is not easy to be the perceptual systems (such as visual or auditory system) to perceive or notice. Through these information hidden in the carrier, can confirm the content creators, buyers, or to send secret information to determine whether the carrier has been tampered with to. Digital watermarking is an important research direction of information hiding technology. At present, is widely used in digital watermarking technology in the information industry of electronic documents.

The application of the other areas. With the development of electronic information technology and computer network, the scope of application of electronic technology continues to expand, has gradually been applied in medicine, environmental protection, automobile, construction, logistics and other fields, the application in the field of environmental protection is more common in some environmental protection mechanism, in order to achieve the purpose of environmental pollution monitoring, to detect environmental pollution the use of electronic technology, can accurately find the sources of pollution, is conducive to the formulation for pollution source control scheme. The application of electronic technology in logistics is mainly some logistics enterprises in the application of electronic technology to collect product information, and electronic equipment installed in the vehicle, the dynamic monitoring of vehicles, transport condition therefore, we through the network shopping to take product, input number on the Internet you can see the goods what is the status of. 


\section{The prospects of Electronic technology development}

The development of electronic technology in China has entered the intelligent and high-speed, high-speed development of electrical products, not only can save material, can only continue to develop energy-saving, electronic technology innovation, in order to better meet the needs of the development of electronic technology in high tech era. Innovation and development are the development direction of today's electronic technology, and actively to the high frequency direction, at the same time, focus on innovation and development, is the key to the future development of the electronic technology development. Reach a higher level. The switching power supply technology is an important branch of electronic technology, innovation is the development of common goals between them. With the continuous development of new technologies, new technology constantly upgrading, but also continue to develop products with more features ${ }^{[5]}$. High speed development of high frequency switching power supply and modular technology will drive the entire electronic technology, better integration of high efficiency and high quality power. The power switch power supply more types, instead will become an inevitable trend of development. With the continuous development of computer technology and network technology, electronic products as the remote control and monitoring technology of terminal products, has been the rapid development of electronic technology, therefore, must be constantly according to the development of people's needs, and the development of a new mechanical and electrical integration products, the rapid development of the network technology in order to adapt.

\section{Summary}

To sum up, the global information economy, electronic technology plays an important role in many industries, is closely related with our life becomes, at present, the development of electronic technology to the intelligent, digital, user-friendly, integrated direction, more widely, the application in human life therefore, must be combined with the development trend of electronic technology, constant innovation and development, in order to meet the needs of the people. Now, the electronic technology is an important new technology revolution, its potential value has been more and more people know and understand, and aroused the concern and attention. Therefore, must be based on a positive, positive towards electronic technology development, and strengthen the research on the theory and practice of electronic technology Investment, give full play to the role of electronic technology.

\section{References}

[1] Weiya Zheng, Lixin Wang. Electronic Technology Foundation. Higher Education Press, 2004, p. 223-253.

[2] Qiangsheng Zhang, Shumei Xu. The new field of electronic technology-- frequency conversion and energy saving. Electronic production. Vol. 4(2003) No. 13, p. 65-67.

[3] Deqing Wu. The practical application of electronic technology. Value engineering. Vol. 30(2010) No. 11, p. 71-72.

[4] Huigu Cheng. The application of electronic technology. Inner Mongolia science and technology and economy. Vol. S1 (2000) No. 23, p. 14-16.

[5] Zhaowen Tan. Outlook twenty-first Century Electronic Technology. The world of electronic components. Vol. 9(2000) No. 43, p. 34-36. 